\title{
CECY FRANCK: DANÇANDO COM PILATES
}

\author{
CECY FRANCK: DANCING WITH PILATES \\ CECY FRANCK: BAILANDO CON PILATES
}

Patrícia Fernandes*, Christiane Garcia Macedo*, Aline Nogueira Haas*

Palavras chave:

Técnicas de

exercício e de

movimento.

Dança.

História.
Resumo: 0 método desenvolvido por Joseph Pilates teve uma forte repercussão junto aos profissionais da dança americanos, tanto em sua prática quanto em sua difusão para a comunidade em geral e demais culturas. Este estudo teve o objetivo de analisar como as relações de Cecy Franck com o Método Pilates influenciaram na inserção deste no Rio Grande do Sul. A pesquisa é de cunho qualitativo com abordagem teórico-metodológica da História Oral, utilizando como principal instrumento de coleta de informações a entrevista. Observando os desdobramentos das carreiras profissionais dos entrevistados, seus depoimentos e as informações já existentes sobre o desenvolvimento do Método Pilates no Brasil constatamos que seu trabalho influenciou na sua difusão.

Abstract: The method developed by Joseph Pilates had strong impact on American dance professionals, both in its practice and in its spreading to the general community and other cultures. This study looks into how Cecy Franck's relationship with the Pilates Method influenced its introduction in the Brazilian state of Rio Grande do Sul. This is a qualitative study under the theoretical and methodological approach of oral history, using interviews as its main tool for collecting information. Looking at the development of the interviewees' professional careers, their testimonials and existing information about the development of the Pilates Method in Brazil, we found that her work influenced its spreading.

Palabras clave: Técnicas de ejercicio y de movimiento. Baile. Historia.
Resumen: El método desarrollado por Joseph Pilates tuvo una fuerte repercusión junto a los profesionales de la danza norteamericana, tanto en su práctica como en su difusión hacia la comunidad en general y a otras culturas. Este estudio tuvo el objetivo de analizar cómo las relaciones de Cecy Franck con el Método Pilates influyeron en la inserción del mismo en Rio Grande do Sul. La investigación es cualitativa con enfoque teórico metodológico de la historia oral, utilizando como principal herramienta para la recopilación de información la entrevista. Observando la evolución de las carreras profesionales de los entrevistados, sus testimonios y las informaciones existentes sobre el desarrollo del Método Pilates en Brasil, constatamos que su trabajo influyó en la difusión del Método.
*Universidade Federal do Rio Grande do Sul. Porto Alegre, RS, Brasil. E-mail: patgatfer@yahoo.com

Recebido em: 20-04-2016 Aprovado em: 17-03-2017

DOI: http://dx.doi.org/10.22456/1982-8918.64224 (c) (i) () Licence 


\section{INTRODUÇÃOO}

Joseph Pilates ${ }^{1}$ criou, na primeira metade do século XX, um método de condicionamento físico que une arte, ciência e promove o desenvolvimento do equilibrio entre corpo e mente (APARICIO; PÉREZ, 2005; PILATES; MILLER, 1998). Ao longo dos anos, elaborou e construiu equipamentos especialmente para a prática desta atividade. Criou mais de quinhentos exercícios incluindo aqueles que se realizam sobre um colchonete no solo². Uniu em seu trabalho princípios das técnicas e filosofias orientais, tendo como fontes a ioga e as artes marciais, e métodos de educação corporal ocidentais, como a Ginástica Médica de Ling $^{3}$ e as técnicas de dança desenvolvidas por Rudolph Laban.

O Método desenvolvido por Pilates teve uma forte repercussão junto aos profissionais da dança americanos, tanto em sua prática quanto em sua difusão para a comunidade em geral e demais culturas. Segundo Siler (2008, p. 14) "[...] boa parte dos primeiros seguidores do Método Pilates, que veio a ensinar, difundir e formar novos professores, pertencia à comunidade da dança e havia procurado Joseph Pilates para a reabilitação de lesões vinculadas à profissão". Essa procura, segundo a autora, deu-se porque o método garantia-lhes melhor saúde física e melhor desempenho na técnica da dança. Esse fato gerou um inevitável diálogo entre algumas técnicas e movimentos da dança moderna nos Estados Unidos que entraram em efervescência aproximadamente na década de 1930, como, por exemplo, a técnica desenvolvida por Martha Graham ${ }^{5}$. Sobre isso Siler acrescenta:

Diversos elementos da dança clássica e moderna contribuíram para a formação do que viria a ser o Método Pilates, da mesma forma que elementos deste influenciaram as técnicas de dança moderna, como as de Martha Graham e de Hanya Holm ${ }^{6}$ (SILER, 2008, p. 14).

Ambiente referência da dança moderna e contemporânea devido aos grandes artistas desta via que lá viveram, os Estados Unidos atraíram, e atraem até hoje, muitos profissionais da área para estudar nas excelentes escolas de formação em dança. Muitos(as) professores(as), coreógrafos(as) e bailarinos(as) brasileiro(as) que deixaram importante contribuição para a dança moderna e contemporânea no país receberam influências norte-americanas na criação e estruturação de suas metodologias (CUNHA; FRANCK, 2004). Dentre essas referências temos Cecy Franck (1924-2000), bailarina, coreógrafa e professora de dança gaúcha, que após formarse na Escola de Educação Física da Universidade Federal do Rio Grande do Sul, onde mais tarde tornou-se professora, especializou-se na escola de Martha Graham, situada em Nova lorque, durante os anos de 1969 e 1971. Ao retornar a Porto Alegre, desenvolveu seu trabalho como coreógrafa e professora baseando-se principalmente na Técnica de Graham (FRANCK, 2013).

Partindo de informações de estudos desenvolvidos anteriormente sobre o trabalho e a trajetória de Cecy Franck (CUNHA; FRANCK, 2004; FRANCK, 2013) e de alguns depoimentos realizados por seus ex-alunos, este estudo tem o objetivo de analisar como as relações de Cecy Franck com o Método Pilates influenciaram na inserção deste no Rio Grande do Sul.

1 Joseph Humbertus Pilates (1883-1967), nascido na Alemanha e, posteriormente, radicado nos Estados Unidos (PÉREZ PONT; APARICIO ROMERO, 2013).

2 Mat Pilates.

3 Desenvolvida por Pehr Henrik Ling (1776-1838), sueco que desenvolveu um sistema gímnico considerado um dos precursores da Educação Física.

4 Rudolf Von Laban (1879-1958). Dançarino, coreógrafo e pesquisador húngaro (BOURCIER, 1987).

5 Martha Graham (1894-1991). Bailarina, coreógrafa e professora de dança americana (BOURCIER, 1987).

6 Hanya Holm (1893-1992) Bailarina, coreógrafa e professora de dança alemã, que viveu nos EUA (BOURCIER, 1987). 


\section{CAMINHOS DA PESQUISA}

Este estudo tem cunho qualitativo com abordagem teórico-metodológica da História Oral, utilizando como principal instrumento de coleta de informações e a entrevista. Entendemos que:

A história oral é um método de pesquisa (histórica, antropológica, sociológica, etc.) que privilegia a realização de entrevistas com pessoas que participaram de, ou testemunharam, acontecimentos, conjunturas, visões de mundo, como forma de se aproximar deste objeto de estudo (ALBERTI, 1989, p. 1-2).

As entrevistas foram realizadas com ex-alunos(as) e bailarinos(as) que trabalharam com Cecy Franck nos anos 1990. Os critérios de inclusão foram: ter desenvolvido uma trajetória profissional relacionada com a dança ou com o Método Pilates posteriormente ao período em que trabalharam com Cecy Franck. Mediante esses critérios entrevistamos as seguintes pessoas: Ana Medeiros ${ }^{7}$, Joca Vergo ${ }^{8}$, Moacir Corrêa ${ }^{9}$, Mônica Dantas ${ }^{10}$, Aline Haas ${ }^{11}$.

Esta pesquisa integra o Projeto Garimpando Memórias ${ }^{12}$, desenvolvido pelo Centro de Memórias do Esporte (CEME) da Universidade Federal do Rio Grande do Sul (UFRGS), que tem como objetivo registrar memórias de pessoas ligadas às diversas práticas corporais (GOELLNER, 2011). O roteiro da entrevista semiestruturada foi desenvolvido a partir do "Manual prático para esclarecimento de procedimentos básicos a serem realizados nas entrevistas", idealizado pela equipe do Projeto Garimpando Memórias do Centro de Memória do Esporte ${ }^{13}$. Ele abordou os seguintes temas: Trajetória de vida das pessoas; Trajetória artística em Método Pilates ou Dança; Trabalhos ou aulas com Cecy Franck; Reflexões sobre as vivências com Cecy. Os entrevistados assinaram um termo de consentimento livre e esclarecido em que concordaram em revelar suas identidades para o registro histórico, pois seria uma perda não divulgar os nomes deles. As entrevistas foram registradas em gravador digital e transformadas em documento escrito. Começando pela transcrição literal, seguida pela conferência de fidelidade, em que se ouve a gravação novamente para verificar se 0 que foi escrito está de acordo com o que foi dito. Depois foi realizado o copidesque, ou seja, a entrevista foi adaptada para o formato de texto escrito em que repetições, lacunas, erros gramaticais e vícios de linguagem são corrigidos, mas sempre lembrando que o texto não pode perder seu formato original ou modificar aquilo que foi expresso. Após todo esse processo, o documento foi devolvido aos entrevistados para que fizessem uma leitura final e aprovassem os dados transcritos. A partir dessa aprovação, foi assinada a carta de cessão, concedendo propriedade e direitos autorais para o CEME. E as entrevistas foram publicadas na íntegra no Repositório Digital da UFRGS.

\footnotetext{
7 Ana Maria Monjelo Medeiros estudou dança moderna com Cecy Franck na segunda metade da década de 1980, formou-se na técnica de Marta Graham em Nova lorque, nos anos 1990. Atualmente, é bailarina e professora de dança, desenvolve uma pesquisa com Tadashi Endo (Japão) na técnica de Butoh.

8 Joaquim Ribas Vergo foi discípulo de Cecy Franck na década de 1990. Atualmente, é diretor da Cia. de dança Joca Vergo, bailarino, professor de dança e de acrobacias aéreas na Cia.Voilá Projectum, Espanha.

9 Moacir Corrêa é bailarino e tecnólogo em dança, último discípulo a conviver com Cecy Franck. Estudou na Escola Nacional de Dança Moderna de Cuba, é fundador do Centro Integrado de Artes Cênicas de Bento Gonçalves, juntamente com Cecy. Atualmente, trabalha como coreógrafo, professor de dança e teatro em escolas de dança de Porto Alegre e outros municípios do Rio Grande do Sul.

10 Mônica Fagundes Dantas foi aluna de Cecy na década de 1980 e 1990, integrante da primeira formação do grupo Choreo. Atualmente é professora adjunta do Curso de Licenciatura em Dança de do Programa de Pós-Graduação em Artes Cênicas da UFRGS.

11 Aline Nogueira Haas foi aluna de Cecy na década de 1990. Atualmente, é professora do Curso de Licenciatura em Dança e do Programa de Pós-graduação em Ciências do Movimento Humano da UFRGS.

12 Aprovado pelo Comitê de Ética da Universidade Federal do Rio Grande do Sul sob o número 2007710.

130 Manual foi atualizado em 2012.
} 
Apresentados os procedimentos, ressaltamos que não estamos trabalhando com a entrevista enquanto "verdade", mas sim com uma versão do passado vivido por essas pessoas (ALBERTI, 2010). Por isso, os dados das entrevistas não foram analisados de maneira isolada, as informações foram relacionadas e problematizadas. A autora citada ainda coloca que:

[...] a postura envolvida com a história oral é genuinamente hermenêutica: o que fascina numa entrevista é a possibilidade de tornar a vivenciar as experiências do outro, a que se tem acesso sabendo compreender as expressões de sua vivência (ALBERTI, 2004, p. 18-19).

Assim, para esse trabalho a entrevista de História Oral se mostra interessante para entendermos os meandros da inserção do Método Pilates, pois, como destaca Portelli, "A primeira coisa que torna a História Oral diferente, portanto, é aquela que nos conta menos sobre eventos do que sobre significados" (1997, p. 31, grifos do original).

Assim, a análise dos dados obtidos nas entrevistas foi realizada por meio da elaboração da seguinte categoria de análise, estruturada de acordo com o objetivo da pesquisa: influências de Cecy Franck no surgimento do Método Pilates no Rio Grande do Sul. Porém, destacamos que ainda são poucas ${ }^{14}$ as publicações que abordam historicamente o Pilates no Brasil. Por esse motivo nossas análises privilegiaram as entrevistas.

\section{CHOREO I - A DANÇA DE CECY E SEUS PASSOS COM O MÉTODO PILATES}

Cecy Franck, gaúcha, natural de Venâncio Aires ${ }^{15}$, foi bailarina, coreógrafa e professora de dança. Iniciou sua aprendizagem na dança quando cursou graduação em Educação Física na Universidade Federal do Rio Grande do Sul (UFRGS). Local onde mais tarde veio a trabalhar como professora universitária. Estudou na escola Lya Bastian Meyer ${ }^{16}$ e na escola de Tony Petzhold ${ }^{17}$, em Porto Alegre/RS; também estudou dança moderna na escola de Nina Verchinina ${ }^{18}$, no Rio de Janeiro.

Em 1969, viajou para os Estados Unidos e formou-se na escola de Dança Moderna de Martha Graham, em Nova lorque. De volta ao Brasil, em 1971, fixou-se em Bento Gonçalves/ RS durante quatro anos, ministrando aulas e aprofundando seus estudos no Clube Aliança. Em 1976, retornou a Porto Alegre e voltou a lecionar dança contemporânea na escola de dança de Tony Petzhold. De 1978 a 1981, trabalhou na Academia Mudança, dirigida por Eva Schul ${ }^{19}$. E, em 1980, fundou uma escola de dança no bairro Bom Fim, chamada "Choreo-Espaço alternativo de Dança", em parceria com Luiz Sayão e Maria Clara Medeiros. Nesse período criou o grupo de Dança Choreo e desenvolveu um trabalho artístico baseado no sistema de Marta Graham (CUNHA; FRANCK, 2004).

O grupo Choreo tinha uma estrutura profissional, embora não pagasse salário aos artistas, realizando produções profissionais de dança com eventuais patrocínios. O espaço era de formação, onde alguns alunos participavam do grupo como estagiários e outros, mais preparados, como integrantes fixos do elenco (DANTAS, 2015).

\footnotetext{
14 A partir de levantamento no Portal de Periódicos da Capes, Scielo, Web of Science e Lilacs, e em livros específicos sobre a temática. 15 Cidade do interior do Rio Grande do Sul.

16 Eliane Clotilde Bastian Meyer Schimitz: bailarina, professora, coreógrafa e pedagoga que em 1943 foi responsável pela Escola Oficial de Dança do Theatro São Pedro, Porto Alegre (CUNHA; FRANCK, 2004).

17 Antônia Seitz Petzhold: bailarina e professora de dança, descendente de imigrantes alemães que residiu em Porto Alegre (CUNHA; FRANCK, 2004). 
Sobre a rotina do Choreo, comenta Ana Medeiros:

[...] 0 trabalho com a Cecy era intenso. E como eu sempre levei a dança muito a sério, nosso trabalho a sério, acho que ela sentia isso e exigia o máximo, sempre o máximo. Nunca chegava ali pela metade. E eu acho que é essa disciplina que eu carrego até hoje. E a Cecy sentava na aula para mostrar um exercício, ela não sentava, estava imersa naquele universo. Quando dizia: 'Agora respira, percebe o spirel na coluna vertebral'. Era o corpo dela inteiro se mexendo, só tu olhar para Cecy, tu via o olhar sentindo aquela movimentação na coluna vertebral. Ela inspirava e transpirava aquilo que ela ensinava (MEDEIROS, 2015, p.4).

Mônica Dantas, que participou como bailarina do grupo Choreo afirma:

[...] a Cecy era muito ortodoxa, muito fiel ao que ela aprendeu e compreendeu no corpo dela e sistematizado durante a estadia que teve na escola de Martha Graham. Então, no início era todo um universo que se abria. Começávamos no chão, o chão de Graham. Depois trabalhávamos o centro e depois as diagonais. Era essa a estrutura, uma hora e meia de aula de técnica de Graham. Bem estruturada, todo o passo a passo, seguindo, claro tinham progressões. E era muito bonito, o chão de Graham principalmente era muito plástico. (DANTAS, 2015, p.7).

Em 1986, o grupo Choreo se desfez. A partir daí, Cecy passou a realizar trabalhos como coreógrafa ou professora de outros grupos de dança da cidade, como o Grupo Phoeni $x^{20}$ e na escola de Alexander Siderof ${ }^{21}$. Ao sair da escola de Siderof abriu um estúdio no Bairro Auxiliadora em sua própria casa onde ministrava aulas de dança contemporânea para seus alunos e alunas (CUNHA; FRANCK, 2004). Tornou-se uma mestra em sua arte, sendo responsável pela formação e incentivo de um grande número de bailarinos e bailarinas de Porto Alegre e do interior do Rio Grande do Sul, muitos dos quais hoje têm uma expressiva carreira na dança e na arte cênica contemporânea nacional e internacional.

Aline Haas afirma: "[...] dona Cecy dava umas aulas para nós lá no Phoenix. E aí, quem se interessou e quem gostou das aulas dela, poderia também fazer aula com ela na casa dela" (HAAS, 2015, p.3). Ana complementa: "Comecei a fazer aulas com a Cecy no Alexander Siderof [...] Comecei ali, depois ela foi para a casa dela, na salinha pequena, mínima [...] Não existia mais o Choreo, mas ela juntava alunos que achava que tinham condições para apresentar algumas coreografias" (MEDEIROS, 2015, p. 4-5).

Como mestra, estimulou muito o crescimento de seus discípulos e alguns se projetaram para estudar fora do país, como foi o caso de Carla Rigon e Ana Medeiros, que também estudaram na escola de Marta Graham, em Nova lorque. Ana em seu depoimento comenta:

E não larguei a Cecy durante quatro anos. No terceiro ano a Cecy disse: 'Acho melhor tu saíres do Brasil, porque aqui não tem como tu te profissionalizares'. A Cecy sempre teve o hábito de abrir as portas para as pessoas. [...] Em Nova lorque fiquei 23 anos. Na escola de Graham, eu fiquei três anos e meio, que é 0 tempo que a gente completa o Trainee Program (MEDEIROS, 2015, p.2).

A relação que Cecy estabelecia com seus alunos estendia-se além das aulas ministradas, criando um ambiente de troca de informações constantes e estimulando sempre a aprendizagem. Essa característica pessoal da Mestra possibilitou que ela conhecesse 0 Método Pilates. Pois Ana e Carla mantiveram contato com Cecy através de cartas, enquanto 
estudavam na escola de Graham. E quando retornavam ao Brasil para visitar parentes sempre a procuravam. "Então todos os anos as meninas voltavam a Porto Alegre e nos enchiam de informações novas da Martha Graham School de Nova lorque. Isso era muito bacana e muito bonito, porque tu vias a transformação nelas, na técnica" (VERGO, 2015, p.2 - 3).

Na década de 1990, na escola de Martha Graham, era comum para a maioria dos alunos a prática do Método Pilates, é o que nos relata Ana Medeiros:

Eu comecei na escola da Graham, através de indicação de uma professora que era a Susyn Quicouchi, filha de Eurico, que foi minha grande mestra e foi professora da Cecy também. Uma bailarina das primeiras gerações da Graham. Ela me indicou o Robert Fitzgerald ${ }^{22}$, que era professor de Pilates. Nunca tinha ouvido falar na estória o que era o Pilates e lá fui eu fazer, porque todos os bailarinos da Graham faziam Pilates e eles tinham um tronco fabuloso (MEDEIROS, 2015, p.7).

Cecy teve contato com o Método Pilates através de Ana e Carla, quando recebeu de presente um livro de Método Pilates: "[...] as gurias lá em Nova lorque, a Ana Medeiros e a Carla Rigon mandaram um livro ${ }^{23}$ para dona Cecy, de Pilates, e a dona Cecy traduziu aqueles exercícios, começou a dar algumas coisas pra nós" (HAAS, 2015, p.4). 0 livro apresenta os exercícios do Método no Mat (solo). Ela passou a utilizá-los no início das suas aulas, antes dos exercícios de Graham, afirmam os entrevistados. Em seu depoimento Aline afirma: "[...] era num período da aula, eu me lembro de que ela dava ou no início ou no final. Tipo assim, ela fazia técnica Graham e aí, falava: Agora vamos fazer os exercícios do Pilates!" (HAAS, 2015, p.5). Mônica Dantas relata: "Então, às vezes ela vinha com seu caderninho de Pilates e dava antes da aula de Graham alguns exercícios de Pilates. No chão, deitados, não saberia dizer qual, mas ela fazia isso eu lembro" (DANTAS, 2015, p. 11-12). Joca informa: "E a partir daí a Cecy começou a introduzir Pilates no início da classe de Marta Graham. Então eram 45min de Pilates de solo, de chão e depois nós entrávamos na classe de Marta Graham" (VERGO, 2015, p.3).

Atualmente, não se sabe ao certo com quem está o original desse livro. Mas sabe-se que Joca Vergo tem uma fotocópia e nos conta: "É um livro de Pilates, de Philip Friedman e Gail Eisen, dedicado a Joseph e Clara Pilates e Romana Khryzanovska [...]" (VERGO, 2015, p.17).

Em 1994, após um momento difícil e delicado de saúde, Cecy Franck decidiu morar perto de sua família, em Bento Gonçalves. Foi quando reencontrou seu aluno Moacir Corrêa, natural da mesma cidade (VERGO, 2015; CORRÊA, 2015). Com esse reencontro deu continuidade ao seu trabalho de ensino e difusão da dança moderna e contemporânea.

Sobre a estrutura das aulas de Cecy neste momento, Corrêa (2015) relata:

O Pilates eu conheci com a Cecy Franck. [...] Cecy, ela me dava uma preparação de Pilates antes de fazer aula. [...] Naquele período em que fazíamos aulas, o Pilates era um condicionamento físico, um preparo que ela me dava. Então eu estava muito focado na técnica de Graham. Nós não falávamos do Pilates. Em alguns momentos de exercícios de Graham ela comentava sobre a semelhança com alguns exercícios de Pilates (CORRÊA, 2015, p. 11-12).

De acordo com esse relato, aparentemente a estrutura das aulas de Cecy era semelhante à estrutura das aulas que ministrava em Porto Alegre. Mas faz-nos supor que nesta fase de seu trabalho em Bento Gonçalves ela talvez tenha se apropriado mais dos

22 Dançarino norte-americano, discípulo de Clara e Joseph Pilates (MEDEIROS, 2015).

23 FRIEDMAN, Philip; EISEN, Gail. The Pilates Method of Physical and Mental Conditioning. (O Método Pilates de Condicionamento Físico e Mental). New York: Penguin, 2004. 
exercícios de Pilates, estabelecendo relações de aproximação através da prática, no uso das duas técnicas, procurando apontar aos alunos as semelhanças entre os exercícios de Pilates e os exercícios de Graham.

\section{CHOREO II - CECY FRANCK E A INFLUÊNCIA DO MÉTODO PILATES NO RIO GRANDE DO SUL}

O método desenvolvido por Joseph Pilates tornou-se muito popular no universo da dança nova-iorquina, pois vários de seus discípulos da primeira geração, que deram sequência ao seu trabalho, eram vinculados à dança e/ou ao teatro. Já na década de 1960, George Balanchine ${ }^{24}$ convidou-o para dar aulas aos jovens bailarinos do American Ballet Theater ${ }^{25}$. Por exemplo, Bruce King, que praticou durante muitos anos com Joseph e Clara Pilates, era integrante da Merce Cunningam Company ${ }^{26}$ e da Alwyn Nicolais Company ${ }^{27}$. Em meados dos anos 1970, ele abriu um estúdio em Nova lorque. Ron Fletcher ${ }^{28}$ era bailarino da escola de Martha Graham e praticava Pilates. Em 1970, abriu um estúdio em Beverly Hills ${ }^{29}$, difundindo 0 método para o mundo das celebridades (BALANCED BODY, 2016).

Elizabeth Ahearn (2013) faz a seguinte colocação:

A combinação de exercício da mente e do corpo, que desenvolve e melhora a força muscular, a amplitude do movimento articular, postura e coordenação, inicialmente atraiu um número de talentosos dançarinos ao original Estúdio Joseph Pilates do numero 939, Oitava Avenida. Entre estes dançarinos incluíam-se figuras bem conhecidas como Hanya Holm, Ted Shawn, Jerom Robbins, Rudolf Laban, George Balanchine, Peral Primus, Suzanne Farrell, e Martha Graham (AHEARN, 2013, p. 249, tradução nossa).

Acreditamos, então, que o fato de Cecy Franck ter se utilizado dos exercícios de solo do Método Pilates em suas classes não foi uma inovação dentro do desenvolvimento histórico do Método, pois essa relação já havia acontecido nos Estados Unidos. Mas acabou se tornando uma semente plantada em seus discípulos de dança aqui no Brasil, mais precisamente, no Rio Grande do Sul. Assim, seus(suas) alunos(as) conheceram um pouco sobre o Método Pilates e souberam de sua existência e prática.

Macedo, Goellner e Haas (2015) informam que nesta época, em Porto Alegre e no restante do estado, não se ouvia falar de Pilates, pois a sua inserção no país iniciava-se lentamente naquele momento. Ainda segundo as autoras, "[...] apesar do Método Pilates ter sido criado no início do século XX, seu aparecimento no Brasil aconteceu apenas na década de 1990" (MACEDO; GOELLNER; HAAS, 2015, p.4).

0 desencadeamento das trajetórias dos discípulos de Cecy fez com que determinados(as) alunos(as) viessem a se deparar com o Método em outras circunstâncias de suas vidas, através de oportunidades surgidas e vieram a se tornar instrutores. Como foi o caso de Aline Haas e Geórgia Ros ${ }^{30}$, que foram alunas de Cecy Franck em diferentes momentos

24 Bailarino e coreógrafo russo radicado em Nova York (BOURCIER, 1987)

25 Companhia de balé fundada em 1934 em Nova York (BOURCIER, 1987).

26 Dançarino e coreógrafo americano (BOURCIER, 1987).

27 Coreógrafo americano (BOURCIER, 1987).

28 Ron Fletcher (1921 - 2011) ator e dançarino de Martha Graham (FLETCHER PILATES, 2016).

29 Beverly Hills é uma cidade localizada no estado americano da Califórnia, no Condado de Los Angeles.

30 Bailarina gaúcha, discípula de Cecy Franck que possui um estúdio de Pilates em Porto Alegre, desde o ano 2000 (HAAS, 2015 ). 
da carreira dela. Aline Haas, instrutora de Pilates há 16 anos e, atualmente, coordenadora do curso de Especialização no Método Pilates da ESEFID/UFRGS, coloca: "[...] a questão do Pilates, foi ela quem me apresentou e aquilo ali ficou na minha vida me acompanhando. E aí, eu vim a ser instrutora de Pilates, porque eu conheci Pilates com ela, com aquela experiência que eu tive [...]" (HAAS, 2015, p.8). Relata ainda:

[...] A Georgia Ros, também tinha conhecido o Pilates através da dona Cecy, tinha morado em Bento e a dona Cecy tinha sido a professora dela de dança. E a dona Cecy mostrou o Pilates para ela, dava aula de Pilates para ela e aí que ela resolveu fazer a formação. Nós duas fizemos a formação juntas em São Paulo (HAAS, 2015, p. 14).

Moacir Corrêa confirma a informação de que Geórgia foi aluna de Cecy Franck pois os dois realizaram uma coreografia juntos: "A primeira foi um pas de deux ${ }^{31}$ com a Geórgia Ros e, depois, 'Perdão Senhor' que fiz um solo" (CORRÊA, 2015, p. 5).

Aline informa que quando residia em Córdoba, na Espanha, em 1992, e cursava seu doutorado, correspondia-se por cartas com Alessandra Tegoni ${ }^{32}$ e ficou sabendo que a amiga estava participando de uma formação em Pilates nos Estados Unidos. Conta que, após o retorno de Alessandra para o Brasil, ela abriu o primeiro estúdio de Pilates em Porto Alegre. Foi através de Alessandra que ficou sabendo que iria ocorrer a primeira formação do método Pilates, em São Paulo, com Romana Krizanowska em 1998 (HAAS, 2015). Mônica confirma que Alessandra Tegoni, em 1998, abriu um estúdio de Pilates em Porto Alegre, pois soube que sua colega Tatiana da Rosa ${ }^{33}$ frequentava as suas aulas (DANTAS, 2015).

Outros discípulos de Cecy seguiram seu percurso na dança, mas em algum momento de suas trajetórias desenvolveram um treinamento físico com Pilates, como foi o caso de Ana Medeiros e Mônica Dantas. Ana relata: "Mas eu não posso negar que Pilates foi minha salvação num determinado momento, especialmente quando eu saí de uma cirurgia da coluna. Foi o que me ajudou a restabelecer e a encontrar o movimento das vértebras" (MEDEIROS, 2015, p.8). Mônica Dantas relata que, bem mais tarde em sua trajetória, acabou tendo um contato com o Método, enquanto fazia seu doutorado em Montreal, no Canadá. Sua colega de curso Miriam Saad, que tem formação em Dança, em Pilates e Body-Mind Centering ${ }^{34}$, fez a preparação corporal de Mônica para um espetáculo solo que elaborava naquele momento (DANTAS, 2015). Moacir Corrêa também comenta que conheceu o método Pilates através de Cecy e, atualmente, está fazendo aulas em Bento Gonçalves (CORRÊA, 2015).

Joca Vergo afirma que até hoje se utiliza do Método de Pilates para a preparação corporal e de seus bailarinos:

Eu continuo dando aulas de contemporâneo aqui em Alicante. E de acrobacia em tecido, sou professor das duas coisas. Sempre eu uso os princípios de Graham e uso técnicas solo de Pilates, muitos exercícios eu continuo usando. [...] Normalmente as pessoas que eu conheci e me ensinaram Pilates eram bailarinos. Que era a Carla Rigon, a Cecy, depois aqui a Alessandra, tinham formação de dança (VERGO, 2015, p. 15-16).

Alessandra Tegoni, conforme Macedo et al. (2014), foi uma das pioneiras na inserção do método no Brasil, abrindo o primeiro estúdio de Pilates na capital gaúcha nos moldes de

31 Pas de deux é a dança executada em conjunto por duas pessoas.

32 Fisioterapeuta e bailarina gaúcha, uma das precursoras na inserção do Método Pilates no Brasil (HAAS, 2015).

33 Bailarina gaúcha, residente em Porto Alegre (DANTAS, 2015). 
uma prática corporal em si, aberta para todos os tipos de público. Mas parece evidente pelos relatos das entrevistas que Cecy foi a primeira pessoa a utilizar do método no Estado. Ela não era instrutora do Método Pilates com formação dentro dos padrões atuais determinados pela Pilates Method Alliance (PMA) ${ }^{35}$. Era professora de Educação Física, coreógrafa e mestra de Graham. E por influência da escola de Graham, recebida por intermédio de Ana e Carla, suas alunas, ela reconheceu sua importância para o trabalho corporal de seus alunos/ bailarinos.

O conhecimento que Cecy adquiriu e desenvolveu sobre o Método Pilates deu-se de forma empírica e autodidata, direcionando-o para um motivo específico relacionado à melhoria do desempenho na dança. Supostamente os mesmos motivos que levaram os alunos da escola americana de Graham a praticar Pilates. Nesse sentido, acreditamos que algumas semelhanças entre os princípios da técnica Graham e os do Método Pilates podem ter levado Cecy e seus discípulos a se identificarem com prática e o ensino de ambos.

A técnica Graham coloca o foco no torso do bailarino, tornando-o a expressão do movimento. Explora a conexão entre emoção e respiração, focando na articulação do tronco e em movimentos espirais, em que seus princípios básicos são a contração/alongamento (extensão). Além disso, a técnica Graham trabalha com o contato com o chão para a colocação da coluna no eixo e com o conceito de Totalidade, onde todo o corpo está coordenado (GRAHAM, 1993). A respiração, as contrações e as espirais dirigem os movimentos das extremidades e os membros são motivados pelos impulsos do core ${ }^{36}$ (LEGG, 2011). A Respiração é um dos aspectos centrais da técnica. Seus ciclos regulares e ritmos permitem o funcionamento do corpo humano e a maneira como ela é utilizada afeta o tipo e a qualidade de movimento criado.

Muitos desses princípios e fundamentos da técnica se assemelham aos seis princípios básicos do Método Pilates, que também focaliza os movimentos a partir do core, compreendendo que eles iniciam a partir desse centro. No Método a respiração também determina o ritmo dos exercícios; a concentração une o trabalho entre mente e corpo; a precisão traz a perfeita definição dos movimentos e o controle corporal; e a fluidez propõe uma dinâmica vigorosa e intensa (SILER, 2000; PANELLI; MARCO, 2009).

Esses pontos em comum entre as duas técnicas não são de difícil observação para alguém que tem conhecimento em dança e também sobre o corpo humano. Talvez a compreensão de Cecy sobre o método tenha alcançado um bom nível para obter resultados significativos com seus bailarinos, devido ao seu conhecimento aprofundado sobre o corpo humano e sua formação na técnica de Graham.

\section{CONSIDERAÇÕES FINAIS}

Observando os desdobramentos das carreiras profissionais dos discípulos de Cecy Franck entrevistados neste estudo, seus depoimentos e as informações já existentes sobre o desenvolvimento do Método Pilates no Brasil, constatamos que seu trabalho influenciou na sua

35 Segundo a PMA, associação profissional de Pilates internacional e agência de certificação para professores, fundada em 2001, nos EUA, os instrutores do Método devem ter uma formação de no mínimo 450 horas de aulas e de estudos (supervisionados ou não) (PILATES METHOD ALLIANCE, 2015).

36 Core em português ganha o significado de 'centro', ou 'núcleo', descrito como uma caixa onde se localizam os músculos abdominais, para vertebrais, glúteos, diafragma, músculos do assoalho pélvico e quadril. Um conjunto de músculos que agem na estabilização do corpo e da coluna vertebral (AKUTHOTA; NADLER, 2004, tradução nossa). 
difusão. Dentro do que se tem conhecimento até o momento, ela foi a primeira pessoa ligada à dança que se utilizou de exercícios do Método como treinamento e preparação corporal de bailarinos no Rio Grande do Sul, vinculado ao trabalho de Martha Graham.

Embora apenas uma das pessoas entrevistadas tenha se tornado instrutor do Método e atue nessa área, os demais praticaram ou ainda praticam Pilates, mas, atualmente, têm suas carreiras dedicadas somente à dança. Essa aproximação entre o Método Pilates e a dança, presente no desenvolvimento do trabalho de Cecy, suscita alguns questionamentos: por que tantos bailarinos se aproximaram do Método Pilates e deram continuidade ao seu trabalho? O que o Método Pilates produz no corpo do bailarino que despertou o interesse de diferentes profissionais da dança?Por que e como o Método Pilates dialoga com a técnica Graham? Nesse sentido, almejamos realizar estudos futuros a fim de investigar tais questões.

Para finalizar, destacamos a necessidade de serem desenvolvidas novas pesquisas de cunho historiográfico sobre o Método Pilates e também sobre a dança no Rio Grande do Sul e no Brasil, pois ainda carecemos de trabalhos científicos com tal aporte nestas temáticas. Cecy Franck foi uma entre as personalidades marcantes e influentes da dança moderna e contemporânea brasileira.

\section{REFERÊNCIAS}

ALBERTI, Verena. História oral e a experiência do CPDOC. Rio de Janeiro: Centro de Pesquisa e Documentação de História Contemporânea do Brasil, 1989.

ALBERTI, Verena. O lugar da História Oral: o fascínio do vivido e as possibilidades de pesquisa. In: Ouvir contar: textos em História Oral. Rio de Janeiro: FGV, 2004. p. 8-25.

ALBERTI, Verena. Manual de história oral. 3. ed. Rio de Janeiro: FGV, 2005.

ALBERTI, Verena. Histórias dentro da História. In: PINSKY, Carla Bassanezi (Org.). Fontes históricas. 2. ed. São Paulo: Contexto, 2010. p. 155-202.

AHEARN, Elizabeth. Pilates its Place in Education. In: FIASCA, Peter; BERGESEN, Amy Baria; DIFFINE, Suzanne Michele. Voices off classical Pilates: Collected Essays. New York: Peter Fiasca, 2013. Cap. 5. p. 247-263.

AKUTHOTA, Venu; NADLER, Scott F. Core strengthening. Archives of Physical Medicine And Rehabilitation, v. 85, n. 1, p.86-92, mar.2004.

APARÍCIO, Esperanza; PÉREZ, Javier. El auténtico Método Pilates: el arte del control. Madrid: Martínez Roca, 2005. p. 25-27.

BALANCED BODY. Origins of Pilates. Disponível em: <https://www.pilates.com/BBAPP/N/pilates/ origins-of-pilates.html>. Acesso em: 22 mar. 2016.

BOURCIER, Paul. História da Dança no Ocidente. São Paulo: Martins Fontes, 1987.

COHEN, Bonnie Bainbridge; The School for Body-mind Centering (Org.). Body-Mind

Centering: and Embodied Approach to Movement, Body and Consciousness. 2011. Disponível em: <http://www.bodymindcentering.com/>. Acesso em: 10 abr. 2016. 
CORREAA, Moacir dos Santos. Depoimento de Moacir dos Santos Corrêa. UFRGS, 2015. Disponível em: <https://sabi.ufrgs.br/F/V8VBH9LBKQEQHAIF8NM86URKD8HJALTRTJH29GIVAF77 9K5B5C-33910? func=full-set-set\&set number $=047916 \&$ set entry=000001\&format=999 $>$ Acesso em: 28 set. 2017.

CUNHA, Morgada; FRANCK, Cecy. Dança: nossos artífices. Porto Alegre: Movimento, 2004.

DANTAS, Mônica Fagundes. Depoimento de Mônica Fagundes Dantas (2). UFRGS, 2015. Disponível em: <https://sabi.ufrgs.br/F/V8VBH9LBKQEQHAIF8NM86URKD8HJALTRTJH29GIVAF77 9K5B5C-40665?func=full-set-set\&set number $=048014 \&$ set entry $=000004 \&$ format $=999>$. Acesso em: 28 set. 2017.

FERREIRA, Marieta de Moraes; AMADO, Janaína (Orgs.). Usos \& Abusos da História Oral. Rio de Janeiro: Fundação Getúlio Vargas, 1996.

FRANCK, Cecy. Dança Moderna: movimentos fundamentais organizados segundo os princípios da Técnica de Martha Graham. Porto Alegre: CEME/UFRGS, 2013. (Coleção Grecco).

FLETCHER PILATES. Program of study. Arizona. Disponível em: < http://www.fletcherpilates. com/programs-events/comprehenive-program>. Acesso em: 11 de abr. 2016.

FRIEDMAN, Philip; EISEN, Gail. The Pilates Method of Physical and Mental Conditioning. New York: Penguin Group, 2004.

GOELLNER, Silvana Vilodre. Práticas em história oral: a experiência do centro de memória do esporte (Esef-Ufrgs). In: ENCONTRO REGIONAL SUL DE HISTÓRIA ORAL: NARRATIVAS, FRONTEIRAS E IDENTIDADES, 6., 2011, Pelotas. Anais...Pelotas: Ufpel, 2011. p. 334 - 340.

GRAHAM, Marta. Memória de Sangue. Porto Alegre: Siciliano, 1993.

HAAS, Aline Nogueira. Depoimento de Aline Nogueira Haas. UFRGS, 2015. Disponível em: < http://www.lume.ufrgs.br/handle/10183/166263>.Acesso em: 28 set. 2017.

LEGG, Joshua. Introduction to Modern Dance Techniques. New Jersey: Princeton Book, 2011.

MACEDO, Christiane Garcia; GOELLNER, Silvana Vilodre; HAAS, Aline Nogueira. Uma história do Método Pilates no Brasil. In: CONGRESSO BRASILEIRO DE PESQUISA EM PILATES, 1., 2014, Bento Gonçalves. Anais do Congresso Brasileiro de Pesquisa em Pilates. Porto Alegre: ESEF/UFRGS, 2014. p. 31.1CD-ROM.

MACEDO, Christiane Garcia; HAAS, Aline Nogueira; GOELLNER, Silvana Vilodre. O Método Pilates no Brasil segundo a narrativa de algumas de suas instrutoras pioneiras. Pensar a Prática, v. 18, n. 3, p.1-13, 2015.

MEDEIROS, Ana Maria Monjeló. Depoimento de Ana Maria Monjeló Medeiros. UFRGS, 2015. Disponível em: < http://www.lume.ufrgs.br/handle/10183/169177>. Acesso em: 28 set. 2017.

PANELLI, Cecília; MARCO, Ademir de. Método Pilates de condicionamento do corpo: um programa para toda a vida. 2. ed. São Paulo: Phorte, 2009.

PÉREZ PONT, Javier; APARICIO ROMERO, Esperanza. Humbertus Joseph Pilates: la biografia. Barcelona: HakaBooks, 2013.

PILATES, Joseph Hubertus; MILLER, William Jhon. The Complete Writings of Joseph Pilates. Philadelphia: Bain Bridge Books, 1998. 
PILATES METHOD ALLIANCE. Visão Geral da Certificação em Pilates. 2015. Disponível em: <http://www.pilatesmethodalliance.org/i4a/pages/index.cfm?pagelD=3567> Acesso em: 10 abr. 2016.

PORTELLI, Alessandro. "O que faz a história oral diferente". Projeto História, n. 14, p. 25-39, fev. 1997.

SILER, Brooke. 0 Corpo Pilates: um guia para o fortalecimento, alongamento e tonificação sem o uso de máquinas. São Paulo: Summus, 2008.

VERGO, Joaquim Ribas. Depoimento de Joaquim Ribas Vergo. UFRGS, 2015. Disponível em: < http://www.lume.ufrgs.br/handle/10183/169183>. Acesso em: 28 set. 2017. 